\title{
Heart disease as a risk factor for dementia
}

This article was published in the following Dove Press journal:

Clinical Epidemiology

25 April 2013

Number of times this article has been viewed

Justin $\mathrm{B} \mathrm{Ng}{ }^{\prime}$

Michele Turek ${ }^{2,3}$

Antoine $\mathrm{M} \mathrm{Hakim}^{4-7}$

'Departments of Neuroscience and Psychology, McGill University,

Montreal, QC, Canada; ${ }^{2}$ Division of Cardiology, The Ottawa Hospital,

Ottawa, ${ }^{3}$ Department of Medicine, University of Ottawa, Ottawa,

${ }^{4}$ Division of Neurology, The Ottawa Hospital, Ottawa, ${ }^{5} \mathrm{Brain}$ and Mind Research Institute, University of Ottawa, Ottawa, ${ }^{6}$ Ottawa Hospital Research Institute, The Ottawa Hospital, Ottawa, ${ }^{7}$ Canadian Stroke Network, Ottawa, ON, Canada
Correspondence: Antoine M Hakim

The University of Ottawa,

24I3-45 I Smyth Road, Ottawa,

ON KIH 8M5, Canada

Tel +l 6135625462

$\mathrm{Fax}+$ I 6135625403

Email ahakim@ohri.ca
Abstract: As life expectancy lengthens, dementia is becoming a significant human condition in terms of its prevalence and cost to society worldwide. It is important in that context to understand the preventable and treatable causes of dementia. This article exposes the link between dementia and heart disease in all its forms, including coronary artery disease, myocardial infarction, atrial fibrillation, valvular disease, and heart failure. This article also explores the cardiovascular risk factors and emphasizes that several of them are preventable and treatable. In addition to medical therapies, the lifestyle changes that may be useful in retarding the onset of dementia are also summarized.

Keywords: Alzheimer's disease, coronary artery disease, myocardial infarction, atrial fibrillation, valvular disease, heart failure, cardiovascular risk factors, prevention

\section{Introduction}

Dementia is a common neurological disorder and is an increasingly prevalent problem, especially among the elderly population. It is estimated there are upwards of 24.3 million cases of dementia presently, with that number expected to double every 20 years, resulting in 81.1 million cases in $2040 .^{1}$ The frequency of dementia is compounded by the growing worldwide population of the elderly ( $>65$ years old), which is estimated to increase (from 606 million in 2000) to nearly 2 billion in $2050 .^{2}$

Dementia is a loss of brain function and overall global cognitive ability. It is the result of progressive impairment in more than one cognitive domain, leading to an eventual loss of the ability to perform all tasks of daily living. ${ }^{3}$ Types of dementia include Alzheimer's disease (AD), vascular dementia (VaD), frontotemporal dementia, dementia with Lewy body, Parkinson's disease-related dementia, and dementia as a result of disease (for example AIDS or multiple sclerosis) ${ }^{4}$ Cognitive impairment is a broad term that generally describes a decline in cognitive functions, and the severity of the impairment ranges from mild cognitive impairment (MCI) to dementia.

When investigating the effects of cognitive decline, many studies use MCI as the main outcome, instead of dementia. It is very important to note that while MCI is only considered an intermediate stage between a normal cognitive state and dementia, individuals with MCI are at an increased risk of progression to dementia, especially in the elderly. ${ }^{5,6}$ Multi-domain MCI, amnestic MCI (aMCI), and non-amnestic MCI (naMCI) all progress to different types of dementia, with the estimated annual progression rates of $12.2 \%, 11.7 \%$, and $4.1 \%$, respectively. ${ }^{7}$ Therefore, even though dementia may evolve from MCI, the increased risk of progression means that it is still important to discuss studies whose main outcome is MCI, as we have done here. By contrast, while the 
presence of the APOE e4 allele is strongly associated with cardiovascular disease as well as cognitive impairment and dementia, it will not be discussed in detail in this review.

Heart disease is defined as any condition that impairs cardiac function regardless of the specific modality that is affected. Heart disease is a growing problem, and the resultant vascular insufficiency has the potential to impair function in other organs, including the brain. ${ }^{8}$ There is an expanding body of literature implicating heart disease as a risk factor for dementia. In addition, a number of studies suggest that cardiovascular risk factors are independently associated with the development of dementia. These risk factors include hypertension, hypercholesterolemia, diabetes, obesity, and smoking. Even though there are many types of dementias and a wide spectrum of vascular cognitive impairment, this review will focus mainly on the two most common, $\mathrm{AD}$ and $\mathrm{VaD},{ }^{9,10}$ as well as the most common variety, mixed dementia that is characterized by multiple cerebral pathologies with prominent vascular involvement. ${ }^{11}$ The purpose of this review is to present the current knowledge base regarding heart disease and its associated risk factors in relation to dementia.

\section{Dementia}

While it may not be surprising that heart disease is a significant cause of $\mathrm{VaD}$, it is perhaps unexpected that more studies are also linking it to $\mathrm{AD}$. $\mathrm{VaD}$ and $\mathrm{AD}$ have very different underlying pathologies. The pathology of $\mathrm{AD}$ is defined by the accumulation of neuritic plaques $(\beta$-amyloid $(A \beta))$ in the extracellular neuropil and neurofibrillary tangles (composed of tau protein) in neurons, ${ }^{12}$ while $\mathrm{VaD}$ is characterized by a cerebrovascular pathology, exhibiting white matter hyperintensities, lacunar infarctions, and ischemic periventricular leukoencephalopathy. ${ }^{13,14}$ There is a large overlap between $\mathrm{AD}$ and $\mathrm{VaD}$ in regard to clinical features and neuropathological changes. ${ }^{15}$ More specifically, both dementias can occur in tandem and share common cardiovascular risk factors which when clustered together can increase the likelihood of dementia independently or through the increased risk of heart disease. ${ }^{16-20}$ For these reasons, a review by Bowler and Hachinski defined $\mathrm{AD}$ as a vascular disorder more than a decade ago. ${ }^{21}$

\section{Heart disease as a risk factor for dementia}

Reduced cerebral blood flow (CBF) due to heart disease of any kind worsens the vascular homeostasis of the brain, and magnifies any cognitive problems caused by the buildup of tau and $A \beta$ proteins. A recent study has shown that dementia patients with a prior history of heart disease are more likely to have structural and functional cardiac abnormalities compared with controls. ${ }^{22}$ Using cardiac magnetic resonance imaging (MRI) as a method to measure cardiac function, this study has also shown that cardiac index, as a marker of overall cardiac function, is positively related to total brain volume and processing speed. ${ }^{23}$ Positive associations have been shown between ischemic heart disease and cognitive impairment on the one hand, and between atherosclerotic cardiovascular disease and cognitive decline on the other. ${ }^{24-26}$ As well, an association between the degeneration of myocardial post-ganglionic sympathetic nerves and the Lewy body variant in Parkinson's disease has been reported. ${ }^{27}$ It is important, however, to focus on more specific types of heart disease and dementia in order to clarify the relative contribution of each entity to cognitive impairment.

\section{Coronary artery disease}

The association between coronary artery disease and cognitive decline, including dementia, is strong. Atherosclerosis plays a major role in the development of both coronary artery disease and dementia. In the Cardiovascular Health Study cohort, the incidence of dementia was higher in those with prevalent coronary artery disease, ${ }^{28}$ and several studies have confirmed that coronary artery disease is associated with cognitive impairment, ${ }^{29-31}$ reduced hippocampal volume, ${ }^{32}$ dementia due to platelet hyperactivity, ${ }^{33}$ and increased senile plaque formation in cortical areas of the brain. ${ }^{34} \mathrm{~A}$ recent study by Graban and colleagues showed that coronary artery disease was observed more frequently in VaD patients. ${ }^{35}$ Cross-section analysis of the AGES-Reykjavik Study by Vidal and colleagues showed that lower scores on each cognitive domain were strongly related to atherosclerotic burden, indirectly estimated by coronary artery calcium (CAC) load. The percentage of dementia significantly increased with quartiles of CAC (Q1 10.3\%, Q2 21.8\%, Q3 29.1\%, Q4 38.8\%), while gray matter, white matter, and total brain tissue volumes decreased. ${ }^{36}$

Coronary artery disease may lead to dementia through its association with brain small vessel disease. ${ }^{37,38}$ Small vessel disease in turn disturbs $\mathrm{CBF}$ regulation and perfusion, disrupts the blood-brain barrier, and leads to an increased susceptibility to neurological insults. ${ }^{39}$ In addition, the failure in small vessel disease to clear excess $A \beta$ produced by cortical neurons contributes to cerebral hemorrhaging and AD pathology. ${ }^{40,41}$ 


\section{Atrial fibrillation (AF)}

$\mathrm{AF}$, the most common cardiac arrhythmia, is an important and modifiable cause of ischemic stroke and results in considerable physical and cognitive disability. While there is still some uncertainty regarding the relationship between $\mathrm{AF}$ and dementia in the absence of stroke, ${ }^{42,43}$ it is clear that AF can be considered a contributor to the onset of dementia. ${ }^{44-47}$ Moreover, there is growing evidence supporting AF as a risk factor for dementia without stroke. ${ }^{48-50}$

Recent data also show an association between AF and AD progression. ${ }^{51}$ In a study of 37,025 patients, 10,161 (27\%) developed AF and 1535 (4.1\%) developed dementia, and AF was independently significantly associated with senile, vascular, and $\mathrm{AD}$ dementia. ${ }^{52}$ The cross-sectional analysis in the Rotterdam study reported that AF exerts its effects only partly through stroke and showed a significant association between $\mathrm{AF}$ and both dementia and cognitive decline, where dementia was twice as common among AF patients than controls. ${ }^{53}$ The strongest association was for $\mathrm{AD}$ with cerebrovascular disease, rather than $\mathrm{VaD} .^{53}$ In a recent analysis of the ONTARGET and TRANSCEND studies by Marzona and colleagues, it was determined that $\mathrm{AF}$ was associated with an increased risk of cognitive decline (hazard ratio [HR] 1.14, 95\% confidence interval [CI] 1.03-1.26) and new dementia (HR 1.14, 95\% CI 1.14-1.49). ${ }^{54}$ In another longitudinal, community-based cohort study by Miyasaka and colleagues, 299 AF subjects were diagnosed with dementia, with an estimated overall incidence rate of 22.5 per 1000 person-years, suggesting a risk of dementia following the development of AF. ${ }^{55}$ Finally, studies show that $\mathrm{AF}$ is associated with brain abnormalities, more specifically, a smaller hippocampal volume and left ventricular hypertrophy. ${ }^{56}$ In addition, in individuals suffering from AF, learning, memory, attention, and executive functions are poorer, ${ }^{57}$ consistent with other studies showing decreased scores on cognitive domain tests in patients with $\mathrm{AF}^{58,59}$

Several mechanisms have been suggested linking AF and dementia. In AF, irregular rapid ventricular rates could lead to decreased cerebral perfusion due to low cardiac output. ${ }^{60-62}$ Another suggested mechanism is the increase in risk of covert cerebral infarction and transient ischemic attacks. ${ }^{63-65} \mathrm{AF}$ also leads to a hypercoagulable state, which may give rise to subclinical cerebral embolism. ${ }^{66,67}$ Finally, experimental data suggest that cerebrovascular disease may precipitate neurodegenerative changes seen as white matter hyperintensities on MRI. ${ }^{68,69}$

\section{Myocardial infarction (MI)}

There are a limited number of studies associating MI with dementia. Men with unrecognized MI have an increased risk of stroke. ${ }^{70}$ Those with MI also share a genetic background with $\mathrm{AD}$, involving abnormalities in cholesterol metabolism and an upregulation in inflammation. Some studies have reported that there is a higher risk of cognitive impairment after MI due to brain hypoperfusion, ${ }^{71}$ and a cross-sectional evaluation in the Rotterdam study showed a positive association between cognitive impairment and prior MI. ${ }^{72}$ In addition, the Bronx Aging Study showed that women with a history of MI had a fivefold increase in the risk of dementia. ${ }^{73}$ Gharacholou and colleagues showed that older subjects with prior MI had measurable cognitive impairment prior to dementia. ${ }^{74}$ Finally, using the results from the Rotterdam and Rotterdam Scan Study, Ikram and colleagues demonstrated that in men, unrecognized MI was associated with an increased risk of dementia (HR 2.14, 95\% CI 1.37-3.35), increased white matter lesion load, and brain infarctions, ${ }^{75}$ supporting the possibility that small vessel disease may be one mechanism by which the risk of dementia increases in MI patients.

However, the impact of MI on dementia remains controversial, and findings lack consistency. ${ }^{76}$ Studies such as the Honolulu-Asia Aging Study found no association between MI and later cognitive impairment. ${ }^{77}$ In a population-based study by Bursi and colleagues, the frequency of MI preceding dementia was identical in the index cases and the control subjects, thus showing no significant evidence of a positive association between MI and dementia. ${ }^{78}$ Therefore, further research is needed to enhance our understanding of the influence of MI on subsequent dementia.

\section{Valve disease}

Studies have reported significant aortic and mitral valve disease in $\mathrm{AD}$ subjects compared with a non-demented control group at autopsy. ${ }^{79}$ Boudoulas and colleagues concluded that left atrial dysfunction increased with chronic mitral valve disease, contributing to AF, thereby increasing risk of dementia. ${ }^{80}$ This is supported by work done by Rodriguez and colleagues in a community-based study of 2680 participants from the Cardiovascular Health Study who underwent MRI analysis. Participants, without prior history of stroke, with left-sided annular or valvular calcification had a 33\% greater risk of covert brain infarcts. ${ }^{81}$ Coupled with other studies demonstrating the presence of brain infarcts in association with calcification of the aortic valve, this supports the association between valve disease and a higher risk of both stroke and cognitive decline. ${ }^{82-84}$ Thus, evaluation of patients 
for aortic and mitral valve disease may be important in the work-up of dementia and its prevention.

\section{Heart failure (HF)}

$\mathrm{HF}$ is defined as insufficient cardiac pump function to provide adequate perfusion to body organs. HF is a growing problem with significant prevalence and mortality rates. In the elderly ( $>65$ years of age), $6 \%-10 \%$ of the population has a diagnosis of HF. ${ }^{85}$ Any number of underlying heart conditions and diseases can lead to HF, including those mentioned in previous sections. According to the HeartMind Study, participants with both HF and coronary artery disease were found to experience similar declines in cognitive function versus non-controls with HF but not coronary artery disease. ${ }^{86}$

Studies have reported that HF is associated with both cognitive impairment and dementia. ${ }^{87-92}$ In a recent pilot case-control study, HF patients had lower scores on a neuropsychological battery designed to assess cognitive functions for dementia than controls in visuospatial, executive function, visual memory, and verbal learning tasks, and showed structural brain changes including right medial temporal lobe atrophy. ${ }^{93}$

The pathophysiological mechanisms that underlie the association between HF and cognitive impairment and dementia are still being investigated. Reduced CBF seems to worsen cognitive impairment associated with HF, and those with heart transplantation had a restoration of $\mathrm{CBF}$ and improved cognitive performance. ${ }^{94-96}$ In $\mathrm{HF}$, low cardiac output combined with impaired cerebral autoregulatory mechanisms, may result in decreased CBF leading to the association with cognitive impairment and dementia. ${ }^{23,97,98}$ HF is also a risk factor for multiple cerebral emboli, which could lead to cognitive impairment. ${ }^{99}$

\section{Cardiovascular risk factors}

Not only is heart disease a risk factor for dementia, but more studies are implicating cardiovascular risk factors as both increasing the risk of dementia through risk of heart diseases and stroke, ${ }^{100}$ and as independent risk factors for dementia. ${ }^{101}$ Ettorre and colleagues reported that in a group of MCI patients, $60 \%$ of them eventually developed dementia, and all subgroups with cardiovascular risk factors had a higher conversion rate to AD. ${ }^{102}$ In addition, many cardiovascular risk factors occur in conjunction with each other, compounding the risk of subtle gray matter changes and subclinical cerebrovascular abnormalities in the brain, as well as dementia. ${ }^{103-106}$ When combined with the presence of the APOE $\varepsilon 4$ allele and stroke, vascular risk factors lead to both vascular and AD pathology. ${ }^{107,108}$

\section{Hypertension and hypotension}

High blood pressure (BP) is a major risk factor for cerebrovascular disorders, including stroke, ischemic white matter lesions, and cerebral infarcts. It is well known that these disorders increase the risk of dementia. ${ }^{64,109,110}$ Less known is that hypertension is an independent risk factor for dementia. The association between hypertension and risk of dementia is prominent, and while a rare study has failed to show this relationship, ${ }^{111}$ the overwhelming majority show a positive association. The high prevalence of hypertension, especially between the age of 30 and 50 years, shows that insight into this relationship is important due to the potential it offers for prevention of cognitive impairment, as we discuss below.

Studies have shown that hypertension is associated with both $\mathrm{VaD}$ and AD. ${ }^{112}$ In a review from the American Journal of Hypertension by Nagai and colleagues, out of seven cited studies, only one did not report that high systolic BP (SBP) and/or diastolic BP (DBP) were risk factors for dementia incidence. ${ }^{113}$ Yamada and colleagues showed that elderly individuals with increased hypertension and SBP had increased risk of VaD. ${ }^{114}$ The Cache County study by Mielke and colleagues further showed that SBP $>160 \mathrm{mmHg}$ at baseline was associated with higher rates of cognitive decline in the elderly, compared with those with lower SBP. A study by Shah and colleagues showed a significant interaction between DBP and plasma $A \beta$ levels, indicating that the $A \beta$-related risk for AD was higher when BP was higher. ${ }^{115}$

Hypertension is also associated with an increased pulse pressure. In the Kungsholmen Project, patients aged $\geq 75$ years with higher pulse pressure had a greater chance of developing dementia than controls. In comparison with the median tertile of pulse pressure $(70-84 \mathrm{mmHg})$, those with higher pulse pressure had relative risk of 1.4 (95\% CI 1.0-2.0; $P=0.04)$ for AD and 1.3 (95\% CI 0.9-1.7) for dementia. ${ }^{116}$ Midlife BP has been reported to have greater effect on the development of AD than late-life hypertension. ${ }^{117}$

Different hypotheses have been offered to elucidate the pathophysiological links between hypertension and dementia. These include hypertension causing vascular alterations leading to lacunar and cortical infarcts and leukoaraiosis, hypertension being responsible for cerebrovascular disease, and hypertension leading to neurobiologic alterations, such as the accumulation of $\beta$-amyloid, causing the onset of dementia. More specifically, hypertension may lead to 
hypoperfusion, or hypoxia of the brain, which can lead to AD pathology. ${ }^{110,118}$ Individuals who underwent antihypertensive treatment had lower neuritic plaques and neurofibrillary tangles than controls. ${ }^{119}$ Hypertension also has an effect on the blood-brain barrier, leading to inflammation or the accumulation of $\beta$-amyloid, causing the development of AD. Brain imaging studies, such as the Honolulu-Asia Aging Study, reported that elevated levels of BP are associated with declines in gray matter volumes in the hippocampus and lateral temporal lobe. ${ }^{120}$

Interestingly, hypotension has also been implicated in the development of dementia. Several longitudinal studies report that hypotension is a risk factor for dementia, but the studies are generally limited to the very elderly. ${ }^{121}$ Most recently, in a study of 599 patients, Nilsson and colleagues reported that low SBP was associated with cognitive decline, dementia, and AD. ${ }^{122}$

\section{Diabetes mellitus}

Diabetes is one of the strongest risk factors for dementia. Diabetes has also been associated with an increased prevalence of cognitive impairment. ${ }^{24}$ In the Rotterdam study of 1999, diabetes mellitus was found to almost double the risk of dementia (relative risk [RR] 1.9 [1.3-2.8]) and AD (RR 1.9 [1.2-3.1]). ${ }^{123}$ The HonoluluAsia Aging study reinforced this association, showing that type 2 diabetes was associated with total dementia, AD, and VaD. ${ }^{124}$ Another study from 2004 suggests that type 2 diabetes might be present in up to $80 \%$ of patients with AD. ${ }^{125}$ A recent review by Beeri and colleagues reported an association between diabetes and risk of dementia and cognitive decline in most but not all epidemiological studies cited. ${ }^{126}$ Brain imaging studies such as the CASCADE Study reported that diabetes is associated with cortical brain atrophy. ${ }^{127}$ Much like other cardiovascular risk factors, the aggregation of diabetes and other risk factors leads to an acceleration in dementia risk. In this setting, the risk of AD is increased threefold. ${ }^{16}$

There are several potential biological mechanisms underlying the association between diabetes mellitus and dementia including the impact of diabetes on cerebral microvessel dysfunction and oxidative stress. ${ }^{128}$ In addition, the role of insulin itself may be important in the potential development of dementia and AD. Insulin degrading enzyme also degrades $\mathrm{A} \beta,{ }^{129}$ and in $\mathrm{AD}$ patients, insulin degrading enzyme levels are reduced, ${ }^{130}$ which could contribute to the accumulation of $\mathrm{A} \beta$ in $\mathrm{AD}$ patients. Additionally, brain insulin signaling may be altered in $\mathrm{AD}$, leading to pathological interactions between the receptor for advanced glycation end products and $\mathrm{A} \beta$ peptides. ${ }^{131}$

\section{Hypercholesterolemia, smoking, and obesity}

The association between hypercholesterolemia and risk of dementia is still controversial. The accumulation of $\beta$-amyloid plaques and the loss of neurons, particularly in the hippocampus, are thought to be central events in the development of AD. Consequently, either overproduction or impaired clearance of $\beta$-amyloid, or both, may be causative in AD. It should be pointed out however that no direct causal relationship has been established between $\mathrm{AD}$ and the dysregulation of cholesterol metabolism. In particular, it is not clear whether the modification of cholesterol homeostasis in AD brains is a cause or a consequence of the disease. ${ }^{132}$ For this reason, some have cautioned against inappropriate treatments. ${ }^{133}$

There are a very limited number of studies on the association between smoking and risk of dementia. A recent meta-analysis of 19 prospective studies by Anstey and colleagues showed that smoking is a risk factor for cognitive decline and dementia. ${ }^{134}$ More importantly smoking is a strong, independent risk factor for stroke, ${ }^{135}$ which is a well established risk factor for dementia. A recent study reported that smoking showed the most consistent inverse association of all cardiovascular risk factors tested with cognitive test results. ${ }^{136}$ As well, neuroimaging studies have associated smoking with reduced gray matter in the prefrontal cortex, anterior cingulate cortex, and temporal lobe in adults, and decreased frontal cortex, posterior cingulum, precuneus, and thalamus in the elderly. ${ }^{137}$ Atrophy in these structures may contribute to the cognitive impairment.

Obesity is a growing problem in modern society and has been linked with the risk of dementia and cognitive impairment. Worldwide, low education is responsible for the largest contribution to dementia, but in the US, this is replaced by physical inactivity. ${ }^{138}$ Body mass index (BMI) is associated with heart disease, in addition to its association with dementia. A recent cardiovascular health study reported that high BMI at midlife (obese, BMI > 30) is associated with higher dementia risk compared with normal weight individuals (HR 1.39, 95\% CI 1.03-1.87). ${ }^{139}$ These results are supported by previous studies by Kivipelto and colleagues and Whitmer and colleagues who also reported an association between midlife obesity and higher dementia risk. ${ }^{140,141}$ Diet is an important, and preventable, risk factor for the development of obesity and subsequently dementia. In particular, the 
consumption of a higher calorie diet rich in unsaturated fatty acids and cholesterol is associated with the development of $\mathrm{AD}$ and cognitive impairment through increased amyloidosis and altered synaptic plasticity. ${ }^{142,143}$

\section{Treatment/prevention}

Since the development of heart disease may be modifiable, the prevention of heart disease through the regulation and moderation of its risk factors is of the utmost importance.

\section{Diet and exercise}

A healthy diet is one modality for prevention of heart disease, but studies have shown very mixed results for diet as an effective method for slowing cognitive decline and dementia. A recent study by Vercambre and colleagues reported that an adherence to a Mediterranean-style diet was not associated with cognitive change in women at higher risk of cognitive decline due to vascular disease or risk factors. ${ }^{144}$ Other studies testing the effects of omega-3 fatty acids, such as those found in dietary fish or fish oil, on cognitive decline found no effect of dietary doses of omega-3 fatty acids on the prevention of cognitive decline. ${ }^{145,146}$

Nevertheless, a healthy diet may indirectly reduce the likelihood of dementia. A prospective observational study of 36,019 subjects by Levitan and colleagues reported that those with diets consistent with the DASH (Dietary Approaches to Stop Hypertension) had a 37\% lower rate of developing $\mathrm{HF},{ }^{147}$ which has been shown previously to be a major risk factor for dementia. As well, multiple studies by Scarmeas and colleagues reported that more optimal adherence to the Mediterranean diet was associated with a reduced risk for $\mathrm{AD}$ as well as conversion to AD in MCI patients. ${ }^{148-150}$ Salt reduction as recommended in the DASH diet is a major tool for reducing hypertension and its vascular consequences including dementia.

Exercise has been implicated in the prevention of cognitive decline and dementia. While studies on the exact relationship are still limited, a recent review by Román and colleagues highlights several studies showing physical activity and exercise as being strongly associated with improved cognition and a lower risk of cognitive decline. ${ }^{151}$ A similar benefit of exercise in reducing AD risk has been reported. ${ }^{152}$ Another systematic review by Aarsland and colleagues demonstrated a significant association between physical exercise and reduced risk of developing VaD. ${ }^{153}$ Finally, a randomized controlled trial by Vreugdenhil and colleagues reported that AD patients who were in the exercise program had increased
Mini-Mental State Examination scores and Instrumental Activities of Daily Living scores compared with those without exercise. ${ }^{154}$

\section{Treatment options}

Since heart disease and cardiovascular risk factors have been associated with dementia, many studies have been conducted to determine whether there is a positive association between lowering such risk factors and lowering the risk of dementia. Antihypertensive medications have been tested extensively. Data from the Cache County Study demonstrated that the use of antihypertensives at baseline was associated with lower incidence of AD. ${ }^{155}$ Also, a meta-analysis of randomized controlled trials by Feigin and colleagues supported the hypothesis that BP lowering may prevent dementia in those with vascular disease. ${ }^{156}$ The cited studies include the Systolic Hypertension in Europe (Syst-Eur) trial, which showed that treating hypertension with an antihypertensive protocol, specifically the calcium channel blocker nitrendipine, resulted in a $50 \%$ reduction in incident cases of dementia. ${ }^{157} \mathrm{~A}$ post-hoc analysis in the PROGRESS trial showed that dementia incidence in patients with recurring stroke was reduced by $34 \%$ when treated with antihypertensives. ${ }^{158}$ The Kungsholmen Study reported that antihypertensive treatment was more effective in reducing dementia among those carrying the APOE $\varepsilon 4$ allele. ${ }^{159}$ These findings are consistent with those of the Honolulu-Asia Aging Study, which demonstrated that the association between high midlife BP and the development of $\mathrm{AD}$ was strongest among those who were never treated for hypertension. ${ }^{160}$

Despite the growing number of positive studies, the SystEur study remains the only recent study with a direct association between antihypertensive use and a decrease in the incidence of dementia. ${ }^{161}$ The Hypertension in the very Elderly Trial Cognitive Function Assessment (HYVET-COG) study, which was a double-blind, placebo-controlled trial, reported that antihypertensive treatment in the elderly did not statistically reduce the incidence of dementia. ${ }^{162}$ A meta-analysis of three randomized, double-blind, placebo controlled trials by McGuinness and colleagues reported that there was no convincing evidence from the trials that BP lowering in hypertensive patients prevented the development of dementia or cognitive impairment. ${ }^{163}$ Despite these mixed results, the use of antihypertensive drugs for lowering midlife BP remains an important treatment option that may prevent the onset of dementia.

How far should BP be lowered? Studies by Lee and colleagues showed that $\mathrm{BP}$ in the range of SBP of 
130-139 $\mathrm{mmHg}$ and DBP of $85-89 \mathrm{mmHg}$ was associated with a substantial increase in stroke risk. ${ }^{164}$ The SPS-3 trial should clarify this important issue, since prehypertension with SBP under $140 \mathrm{mmHg}$ is frequently not treated aggressively. ${ }^{165}$

Data for an association between statins and the prevention of $\mathrm{AD}$ neurodegeneration are mixed. Statins are used to lower cholesterol levels. A recent review highlights the controversial nature of statin use, reporting that statin users have a lower prevalence of $\mathrm{AD}$, while also showing that there is no or only a modest decreased risk of AD. ${ }^{166}$ Another review by Wolozin and colleagues confirms this finding. ${ }^{167}$

Treatment of evident heart disease could also prove beneficial for the prevention of dementia. For example, Stanek and colleagues showed that when treated, HF patients improved their performance on cognitive tests. ${ }^{168}$ Puccio and colleagues reported that AF patients treated with an anticoagulant, warfarin, showed better scores at the Clinical Dementia Rating Scale, the Geriatric Depression Scale, and the Global Deterioration Scale, suggesting a neuroprotective role. ${ }^{169}$ Long-term warfarin is protective against the development of dementia in subjects with AF. ${ }^{170}$

Another drug, donepezil, an acetylcholinesterase inhibitor, has shown promise as an anti-AD drug. In studies on mice, donepezil prevents cardiac rupture during the acute phase of MI through its inhibition of the enzymatic matrix metalloproteinase-9 (MMP-9), as well as through its prevention of pumping failure and cardiac remodeling. ${ }^{171}$ Inhibiting the enzymatic activity of MMP-9 can be an effective treatment for AD. ${ }^{172}$

In the Cardiovascular Health Study, Sink and colleagues reported that angiotensin converting enzyme (ACE) inhibitors might protect against dementia beyond control of BP. Centrally active ACE inhibitors that cross the blood-brain barrier were associated with 65\% less decline on the mini-mental state exam when compared with other antihypertensive drugs. ${ }^{173}$ In another study, the use of ACE inhibitors in HF patients was associated with an improvement in cognitive performance, and the probability of improvement increased with increasing dosage and longer treatment duration..$^{71}$

\section{Conclusion}

Heart disease as well as cardiovascular risk factors, particularly if they manifest in midlife, are associated with the eventual development of dementia later in life. Early prevention and treatment could potentially mitigate the onset of dementia. However, further research is still needed to find the most effective methods of dementia prevention and to better elucidate the vascular mechanisms of this disorder.

\section{Disclosure}

The authors report no conflicts of interest in this work.

\section{References}

1. Ferri CP, Prince M, Brayne C, et al. Global prevalence of dementia: a Delphi consensus study. Lancet. 2005;366:2112-2117.

2. United Nations, World Population Ageing 1950-2050, Population Division, DESA, United Nations, New York. ST/ESA/SER.A/207, 2002.

3. Mathers C, Leonard M. Global burden of dementia in the year 2000: summary of methods and data sources. Geneva: World Health Organization; 2000.

4. Ritchie K, Lovestone S. The dementias. Lancet. 2002;360(9347): 1759-1766.

5. Ganguli M, Snitz BE, Saxton JA, et al. Outcomes of mild cognitive impairment depend on definition: a population study. Arch Neurol. 2011;68(6):761-767.

6. Fleisher AS, Sowell BB, Taylor C, Gamst AC, Petersen RC, Thal LJ. Clinical predictors of progression to Alzheimer disease in amnestic mild cognitive impairment. Neurology. 2007;68(19):1588-1595.

7. Hughes TF, Snitz BE, Ganguli M. Should mild cognitive impairment be subtyped? Current Opinion in Psychiatry. 2011;24(3):237-242.

8. Wolozin B, Bednar MM. Interventions for heart disease and their effects on Alzheimer's disease. Neurol Res. 2006;28:630-636.

9. Paglieri C, Bisbocci D, Caserta M, et al. Hypertension and cognitive function. Clin Exp Hypertens. 2008;30(8):701-710.

10. Whitehouse PJ, Sciulli CG, Mason RM. Dementia drug development: use of information systems to harmonize global drug development. Psychopharmacol Bull. 1997;33(1):129-133.

11. Richard E, Ligthart SA, Moll van Charante EP, van Gool WA. Vascular risk factors and dementia - towards prevention strategies. Neth $\mathrm{J} \mathrm{Med}$. 2010;68(10):284-290.

12. Dickson DW. The pathogenesis of senile plaques. $J$ Neuropathol Exp Neurol. 1997;56:321-339.

13. Iemolo F, Duro G, Rizzo C, et al. Pathophysiology of vascular dementia. Immun Ageing. 2009;6:13.

14. Roman GC. Vascular dementia: distinguishing characteristics, treatment, and prevention. J Am Geriatr Soc. 2003;51:S296-S304.

15. Rosendorff C, Beeri MS, Silverman JM. Cardiovascular risk factors for Alzheimer's disease. Am J Geriatr Cardiol. 2007;16:143-149.

16. Luchsinger JA, Reitz C, Honig LS, Tang MX, Shea S, Mayeux R. Aggregation of vascular risk factors and risk of incident Alzheimer disease. Neurology. 2005;65(4):545-551.

17. Expert Panel on Detection, Evaluation, and Treatment of High Blood Cholesterol in Adults. Executive Summary of The Third Report of The National Cholesterol Education Program (NCEP) Expert Panel on Detection, Evaluation, and Treatment of High Blood Cholesterol in Adults (Adult Treatment Panel III). JAMA. 2001;285: 2486-2497.

18. Kwon HM, Kim BJ, Lee SH, Choi SH, Oh BH, Yoon BW. Metabolic syndrome as an independent risk factor of silent brain infarction in healthy people. Stroke. 2006;37(2):466-470.

19. Yaffe K. Metabolic syndrome and cognitive disorders: is the sum greater than its parts? Alzheimer Dis Assoc Disord. 2007;21:167-171.

20. Langa KM, Foster NL, Larson EB. Mixed dementia: emerging concepts and therapeutic implications. JAMA. 2004;292(23):2901-2908.

21. Bowler J, Hachinski V. Vascular dementia. In: Ginsberg M, Bogousslavsky J, editors. Cerebrovascular Disease: Pathophysiology, Diagnosis, and Management. Oxford, UK: Science Ltd; 1998:1126-1144.

22. Reitz C, Brickman AM, et al. Frequency of subclinical heart disease in elderly persons with dementia. Am J Geriatr Cardiol. 2007; 16(3):183-188. 
23. Jefferson AL, Himali JJ, Beiser AS, et al. Cardiac index is associated with brain aging: the Framingham Heart Study. Circulation. 2010; 122(7):690-697.

24. Halling A, Berglund J. Association of diagnosis of ischaemic heart disease, diabetes mellitus and heart failure with cognitive function in the elderly population. Eur J Gen Pract. 2006;12:114-119.

25. Laughlin GA, McEvoy LK, von Mühlen D, et al. Sex differences in the association of Framingham Cardiac Risk Score with cognitive decline in community-dwelling elders without clinical heart disease. Psychosom Med. 2011;73(8):683-689.

26. Wolf PA. Contributions of the Framingham Heart Study to stroke and dementia epidemiologic research at 60 years. Arch Neurol. 2012; 69(5):567-571.

27. Watanabe M, Takeda T, Nakamagoe K, Tamaoka A. Sequential imaging analysis using MIBG scintigraphy revealed progressive degeneration of cardiac sympathetic nerve in Parkinson's disease. Eur J Neurol. 2011;18(7):1010-1013.

28. Newman A, Fitzpatrick A, Lopez O, et al. Dementia and Alzheimer's disease incidence in relationship to cardiovascular disease in the Cardiovascular Health Study cohort. J Am Geriatr Soc. 2005:53(7):1101-1107.

29. Roberts RO, Knopman DS, Geda YE, Cha RH, Roger VL, Petersen RC. Coronary heart disease is associated with non-amnestic mild cognitive impairment. Neurobiol Aging. 2010;31(11):1894-1902.

30. Rosengart TK, Sweet J, Finnin EB, et al. Neurocognitive functioning in patients undergoing coronary artery bypass graft surgery or perfuctaneous coronary intervention: evidence of impairment before intervention compared with normal controls. Ann Thorac Surg. 2005;80(4):1327-1334; discussion 1334-1335.

31. Freiheit EA, Hogan DB, Eliasziw M, et al. A dynamic view of depressive symptoms and neurocognitive change among patients with coronary artery disease. Arch Gen Psychiatry. 2012;69(3):244-255.

32. Koschack J, Irle E. Small hippocampal size in cognitively normal subjects with coronary artery disease. Neurobiol Aging. 2005;26:865-871.

33. Stellos K, Katsiki N, Tatsidou P, Bigalke B, Laske C. Association of platelet activation with vascular cognitive impairment: implications in dementia development? Curr Vasc Pharmacol. Epub January 20, 2012.

34. Soneira CF, Scott TM. Severe cardiovascular disease and Alzheimer's disease: senile plaque formation in cortical areas. Clin Anat. 1996;9: $118-127$.

35. Graban A, Bednarska-Makaruk M, Bochynska A, LipczynskaLojkowska W, Ryglewicz D, Wehr H. Vascular and biochemical risk factors of vascular dementia after lacunar strokes $(\mathrm{S}-\mathrm{VaD})$ and after multiinfarcts in strategic areas (M-VaD). J Neurol Sci. 2009;283(1-2):116-118.

36. Vidal JS, Sigurdsson S, Jonsdottir MK, et al. Coronary artery calcium, brain function and structure: the AGES-Reykjavik Study. Stroke. 2010;41:891-897.

37. Rosano C, Naydeck B, Kuller LH, et al. Coronary artery calcium: associations with brain magnetic resonance imaging abnormalities and cognitive status. J Am Geriatr Soc. 2005;53:609-615.

38. Kovacic JC, Castellano JM, Fuster V. The links between complex coronary disease, cerebrovascular disease, and degenerative brain disease. Ann N Y Acad Sci. 2012;1254:99-105.

39. Kovacic JC, Moreno P, Nabel EG, et al. Cellular senescence, vascular disease, and aging: part 2 of a 2-part review: clinical vascular disease in the elderly. Circulation. 2011;123:1900-1910.

40. Bell RD, Zlokovic BV. Neurovascular mechanisms and blood-brain barrier disorder in Alzheimer's disease. Acta Neuropathol. 2009;118: 103-113.

41. Itoh Y, Yamada M, Hayakawa M, Otomo E, Miyatake T. Cerebral amyloid angiopathy: a significant cause of cerebellar as well as lobar cerebral hemorrhage in the elderly. J Neurol Sci. 1993;116:135-141.

42. Kwok CS, Loke YK, Hale R, et al. Atrial fibrillation and incidence of dementia: a systematic review and meta-analysis. Neurology. 2011;76:914-922.

43. Tamam B, Taşdemir N, Tamam Y. The prevalence of dementia three months after stroke and its risk factors. Turk Psikiyatri Derg. 2008;19(1):46-56. Turkish.
44. Rastas S, Verkkoniemi A, Polvikoski T, et al. Atrial fibrillation, stroke, and cognition: a longitudinal population-based study of people aged 85 and older. Stroke. 2007;38:1454-1460.

45. Barba R, Martinez-Espinosa S, Rodriguez-Garcia E, Pondal M, Vivancos J, Del Ser T. Poststroke dementia: clinical features and risk factors. Stroke. 2000;31:1494-1501.

46. Zhou DH, Wang JY, Li J, Deng J, Gao C, Chen M. Study on frequency and predictors of dementia after ischemic stroke: The Chongging Stroke study. J Neurol. 2004;251:421-427.

47. Marini C, Baldassarre M, Russo T, et al. A. Burden of first-ever ischemic stroke in the oldest old: evidence from a population-based study. Neurology. 2004;62:77-81.

48. Ratcliffe PJ, Wilcock GK. Cerebrovascular disease in dementia: the importance of atrial fibrillation. Postgrad Med J. 1985;61(713): 201-204.

49. O’Connell JE, Gray CS, French JM, et al. Atrial fibrillation and cognitive function: case-control study. J Neurol Neurosurg Psychiatry. 1998;65:386-389.

50. Sabatini T, Frisoni GB, Barbisoni P, et al. Atrial fibrillation and cognitive disorders in older people. J Am Geriatr Soc. 2000;48:387-390.

51. Mielke MM, Rosenberg PB, Tschanz J, et al. Vascular factors predict rate of progression in Alzheimer disease. Neurology. 2007;69: 1850-1858.

52. Bunch TJ, Weiss JP, Crandall BG, et al. Atrial fibrillation is independently associated with senile, vascular, and Alzheimer's dementia. Heart Rhythm. 2010;7:433-437.

53. Ott A, Breteler MM, de Bruyne MC, van HF, Grobbee DE, Hofman A. Atrial fibrillation and dementia in a population-based study. The Rotterdam Study. Stroke. 1997;28(2):316-321.

54. Marzona I, O’Donnell M, Teo K, et al. Increased risk of cognitive and functional decline in patient with atrial fibrillation: results of the ONTARGET and TRANSCEND studies. CMAJ. 2012;184(6):E329-E336.

55. Miyasaka Y, Barnes ME, Petersen RC, et al. Risk of dementia in strokefree patients diagnosed with atrial fibrillation: data from a communitybased cohort. Eur Heart J. 2007;28:1962-1967.

56. Wozakowska-Kapłon B, Opolski G, Kosior D, Jaskulska-Niedziela E, Maroszyńska-Dmoch E, Włosowicz M. Cognitive disorders in elderly patients with permanent atrial fibrillation. Kardiol Pol. 2009;67:487-493.

57. Knecht S, Oelschlager C, Duning T, et al. Atrial fibrillation in stroke free patients is associated with memory impairment and hippocampal atrophy. Eur Heart J. 2008;29:2125-2132.

58. Kermode-Scott B. Atrial fibrillation increases the risk of cognitive decline and need for long term care. BMJ. 2012;344:e1591.

59. Schrader J. The significance of arterial hypertension for the development of dementia. MMW Fortschr Med. 2004;146(47):40-42.

60. Petersen P, Kastrup J, Videbaek R, Boysen G. Cerebral blood flow before and after cardioversion of atrial fibrillation. J Cereb Blood Flow Metab. 1989;9:422-425.

61. Duron E, Hanon O. Atrial fibrillation and cognitive function. Psychol. Neuropsychiatr Vieil. 2010;8:209-214.

62. Morrison TB, Bunch TJ, Gersh BJ. Pathophysiology of concomitant atrial fibrillation and heart failure: implications for management. Nat Clin Pract Cardiovasc Med. 2009;6:46-56.

63. Ezekowitz MD, James KE, Nazarian SM, et al; for the Veterans Affairs Stroke Prevention in Nonrheumatic Atrial Fibrillation Investigators. Silent cerebral infarction in patients with nonrheumatic atrial fibrillation. Circulation. 1995;92(8):2178-2182.

64. Vermeer SE, Prins ND, den Heijer T, Hofman A, Koudstaal PJ, Breteler MM. Silent brain infarcts and the risk of dementia and cognitive decline. N Engl J Med. 2003;348:1215-1222.

65. Zito M, Muscari A, Marini E, Di Iorio A, Puddu GM, Abate G. Silent lacunar infarcts in elderly patients with chronic non valvular atrial fibrillation. Aging (Milano). 1996;8:341-346.

66. Choudhury A, Lip GY. Atrial fibrillation and the hypercoagulable state: from basic science to clinical practice. Pathophysiol Haemost Thromb. $2003 ; 33: 282-289$. 
67. Barber M, Tait RC, Scott J, Rumley A, Lowe GD, Stott DJ. Dementia in subjects with atrial fibrillation: hemostatic function and the role of anticoagulation. J Thromb Haemost. 2004;2:1873-1878.

68. Kalaria RN. The role of cerebral ischemia in Alzheimer's disease. Neurobiol Aging. 2000;21:321-330.

69. Longstreth WT Jr, Manolio TA, Arnold A, et al. Clinical correlates of white matter findings on cranial magnetic resonance imaging of 3301 elderly people: the Cardiovascular Health Study. Stroke. 1996;27: 1274-1282.

70. Ikram MA, Hollander M, Bos MJ, et al. Unrecognized myocardial infarction and the risk of stroke: the Rotterdam Study. Neurology. 2006;67:1635-1639

71. Zuccala G, Onder G, Pedone C, et al. Hypotension and cognitive impairment: selective association in patients with heart failure Neurology. 2001;57:1986-1992.

72. Breteler MM, Claus JJ, Grobbee DE, et al. Cardiovascular disease and distribution of cognitive function in elderly people: the Rotterdam Study. BMJ. 1994;308:1604-1608.

73. Aronson MK, Ooi WL, Morgenstern H, et al. Women, myocardial infarction, and dementia in the very old. Neurology. 1990;40:1102-1106.

74. Gharacholou SM, Reid KJ, Arnold SV, et al. Cognitive impairment and outcomes in older adult survivors of acute myocardial infarction: findings from the translational research investigating underlying disparities in acute myocardial infarction patients' health status registry. Am Heart J. 2011;162(5):860-869.

75. Ikram MA, Oijen M, Jong FJ, et al. Unrecognized myocardial infarction in relation to risk of dementia and cerebral small vessel disease. Stroke. 2008;39(5):1421-1426.

76. Grubb NR, Simpson C, Fox KA. Memory function in patients with stable, moderate to severe cardiac failure. Am Heart J. 2000;140:1-5.

77. Petrovitch H, White L, Masaki KH, et al. Influence of myocardial infarction, coronary artery bypass surgery, and stroke on cognitive impairment in late life. Am J Cardiol. 1998;81:1017-1021.

78. Bursi F, Rocca WA, Killian JM, et al. Heart disease and dementia: a population-based study. Am J Epidemiol. 2006;163:135-141.

79. Corder E, Ervin JF, Lockhart E, Szymanski MH, Schmechel DE, Hulette CM. Cardiovascular damage in Alzheimer disease: autopsy findings from the Bryan ADRC. J Biomed Biotechnol. 2005;2005(2):189-197.

80. Boudoulas KD, Sparks EA, Rittgers SE, Wooley CF, Boudoulas H. Factors determining left atrial kinetic energy in patients with chronic mitral valve disease. Herz. 2003;28:437-444.

81. Rodriguez CJ, Bartz TM, Lonstreth WT Jr, et al. Association of annular calcification and aortic valve sclerosis with brain findings on magnetic resonance imaging in community dwelling older adults: the cardiovascular health study. J Am Coll Cardiol. 2011;57(21):2172-2180.

82. Oliveira-Filho J, Massaro AR, Yamamoto F, Bustamante L, Scaff M. Stroke as the first manifestation of calcific aortic stenosis. Cerebrovasc Dis. 2000;10:413-416.

83. de la Torre JC. Cardiovascular risk factors promote brain hypoperfusion leading to cognitive decline and dementia. Cardiovasc Psychiatry Neurol. 2012;2012:367516.

84. Belohlavek M, Jiamsripong P, Calleja AM, et al. Patients with Alzheimer disease have altered transmitral flow: echocardiographic analysis of the vortex formation time. J Ultrasound Med. 2009 Nov;28(11):1493-1500.

85. Giamouzis G, Triposkiadis F, Butler J, Westermann D, Giannakoulas G. Heart failure. Cardiol Res Pract. 2011;2011:159608.

86. Almeida, OP, Beer C, Lautenschlager NT, Arnolda L, Alfonso H, Flicker L. Two-year course of cognitive function and mood in adults with congestive heart failure and coronary artery disease: the HeartMind Study. Int Psychogeriatr. 2012;24(1):38-47.

87. Trojano L, Incalzi RA, Acanfora D, Picone C, Mecocci P, Rengo F. Cognitive impairment: a key feature of congestive heart failure in the elderly. J Neurol. 2003;250(12):1456-1463.

88. Vogels RLC, Weinstein HC, Schroeder-Tanka JM. Cognitive impairment in heart failure: a systematic review of literature. Eur J Heart Fail. 2006;5(1):33-34.
89. Lavery L, Vander Bilt J, Chang CC, Saxton JA, Ganguli M. The association between congestive heart failure and cognitive performance in a primary care population of elderly adults: the Steel Valley Seniors Survey. Int Psychogeriatr. 2007;2:215-225.

90. Sauve MJ, Lewis WR, Blankenbiller M, Rickabaugh B, Pressler SJ. Cognitive impairments in chronic heart failure: a case controlled study. $J$ Card Fail. 2009;15:1-10.

91. Qiu C, Winblad B, Marengoni A, Klarin I, Fastbom J, Fratiglioni L. Heart failure and risk of dementia and Alzheimer disease: a populationbased cohort study. Arch Intern Med. 2006;166(9):1003-1008.

92. Polidori CM, Mariani E, Mecocci P. Congestive heart failure and Alzheimer's disease. Neurol Res. 2006;28(6):588-594.

93. Beer C, Ebenezer E, Fenner S, et al. Contributors to cognitive impairment in congestive heart failure: a pilot case-control study. Intern Med J. 2009;39(9):600-605.

94. Alves TC, Rays J, Fraguas R Jr, et al. Localized cerebral blood flow reductions in patients with heart failure: a study using 99mTc- HMPAO SPECT. J Neuroimaging. 2005;15:150-156.

95. Loncar G, Bozic B, Lepic T, et al. Relationship of reduced cerebral blood flow and heart failure severity in elderly males. Aging Male. 2011;14(1):59-65.

96. Gruhn N, Larsen FS, Boesgaard S, et al. Cerebral blood flow in patients with chronic heart failure before and after heart transplantation. Stroke. 2001;32(11):2530-2533.

97. Jefferson AL, Poppas A, Paul RH, Cohen RA. Systemic hypoperfusion is associated with executive dysfunction in geriatric cardiac patients. Neurobiol Aging. 2007;28(3):477-483.

98. Triposkiadis F, Karayannis G, Giamouzis G, Skoularigis J, Louridas G, Butler J. The sympathetic nervous system in heart failure. Physiology, pathophysiology, and clinical implications. J Am Coll Cardiol. 2009;54(19):1747-1762.

99. Pullicino PM, Hart J. Cognitive impairment in congestive heart failure? Embolism vs hypoperfusion. Neurology. 2001;57(11):1945-1946.

100. Shprakh VV, Suvorova IA. Post-stroke vascular dementia: risk factors and clinical neuro-imaging features. Adv Gerontol. 2010;23(2):293-300.

101. Alonso A, Mosley TH Jr, Gottesman RF, et al. Risk of dementia hospitalization associated with cardiovascular risk factors in midlife and older age: the Atherosclerosis Risk in Communities (ARIC) study. J Neurol Neurosurg Psychiatry. 2009;80:1194-1201.

102. Ettorre, E, Cerra E, Marigliano B. Role of cardiovascular risk factors (CRF) in the patients with mild cognitive impairment (MCI). Arch Gerontol Geriatr. 2012;54(2):330-332.

103. de Toledo Ferraz Alves TC, Scazufca M, Squarzoni P, et al. Subtle gray matter changes in temporo-parietal cortex associated witho cardiovascular risk factors. Journal of Alzheimer's Disease. 2011;27:575-589.

104. Schwartz E, Wicinski B, Schmeidler J, Haroutunian V, Hof PR. Cardiovascular risk factors affect hippocampal microvasculature in early AD. Transl Neurosci. 2010;1(4):292-299.

105. Skoog I, Gustafson D. Update on hypertension and Alzheimer's disease. Neurol Res. 2006;28(6):605-611.

106. Weiner M, Rosenberg R, Womack K, et al. Atherosclerosis risk factors in American Indians with Alzheimer's disease: preliminary findings. Alzheimer Dis Assoc Disord. 2008;22(3):245-248.

107. Mielke MM, Leoutsakos J-M, Tschanz JT. Interaction between vascular factors and the APOE $\varepsilon 4$ allele in predicting rate of progression in Alzheimer's disease. J Alzheimers Dis. 2011;26(1):127-134.

108. Jin YP, Ostbye T, Feightner JW, Di Legge S, Hachinski V. Joint effect of stroke and APOE 4 on dementia risk: the Canadian Study of Health and Aging. Neurology. 2008;70:9-16.

109. Celle S, Annweiler C, Pichot V, et al. Association between ambulatory 24-hour blood pressure levels and brain volume reduction: a cross-sectional elderly population-based study. Hypertension. 2012; 60(5):1324-1331.

110. de la Torre JC. Critically attained threshold of cerebral hypoperfusion: the CATCH hypothesis of Alzheimer's pathogenesis. Neurobiol Aging. 2000;21:331-342. 
111. Johnson KC, Margolis KL, Espeland MA, et al. A prospective study of the effect of hypertension and baseline blood pressure on cognitive decline and dementia in postmenopausal women: the Women's Health Initiative Memory Study. J Am Geriatr Soc. 2008;56(8): 1449-1458.

112. Staessen JA, Richart T, Birkenhager WH. Less atherosclerosis and lower blood pressure for a meaningful life perspective with more brain. Hypertension. 2007;49:389-400.

113. Nagai M, Hoshide S, Kario K. Hypertension and dementia. Am J Hypertens. 2010;23:116-124.

114. Yamada M, Kasagi F, Sasaki H, Masunari N, Mimori Y, Suzuki G. Association between dementia and midlife risk factors: the Radiation Effects Research Foundation Adult Health Study. J Am Geriatr Soc. 2003;51:410-414.

115. Shah NS, Vidal J-S, Masaki K, et al. Midlife blood pressure, plasma $\beta$-amyloid, and the risk for Alzheimer disease: The Honolulu Asia Aging Study. Hypertension. 2012;59(4):780-786.

116. Franklin SS, Khan SA, Wong ND, Larson MG, Levy D. Is pulse pressure useful in predicting risk for coronary heart disease? The Framingham Heart Study. Circulation. 1999;100:354-360.

117. Qiu C, Winblad B, Fratiglioni L. The age-dependent relation of blood pressure to cognitive function and dementia. Lancet Neurol. 2005;4:487-499.

118. Kalback W, Esh C, Castaño EM, et al. Atherosclerosis, vascular amyloidosis and brain hypoperfusion in the pathogenesis of sporadic Alzheimer's disease. Neurol Res. 2004;26:525-539.

119. Hoffman LB, Schmeidler J, Lesser GT, et al. Less Alzheimer disease neuropathology in medicated hypertensive than nonhypertensive persons. Neurology. 2009;72(20):1720-1726.

120. de Toledo Ferraz Alves TC, Ferreira LK, Wajngarten M, Busatto GF. Cardiac disorders as risk factors for Alzheimer's disease. J Alzheimers Dis. 2010;20(3):749-763.

121. Kennelly SP, Lawlor BA, Kenny RA. Blood pressure and the risk for dementia-A double edged sword. Ageing Res Rev. 2009;8(2):61-70.

122. Nilsson SE, Read S, Berg S, Johansson B, Melander A, Lindblad U. Low systolic blood pressure is associated with impaired cognitive function in the oldest old: longitudinal observations in a population-based sample 80 years and older. Aging Clin Exp Res. 2007;19:41-47.

123. Ott A, Stolk RP, van Harskamp F, Pols HA, Hofman A, Breteler MM. Diabetes mellitus and the risk of dementia: the Rotterdam Study. Neurology. 1999;53(9):1937-1942.

124. Peila R, Rodriguez BL, Launer LJ. Type 2 diabetes, APOE gene, and the risk for dementia and related pathologies: the Honolulu-Asia Aging Study. Diabetes. 2002;51(4):1256-1262.

125. Janson J, Laedtke T, Parisi JE, O’Brien P, Petersen RC, Butler PC. Increased risk of type 2 diabetes in Alzheimer disease. Diabetes. 2004; 53(2):474-481.

126. Beeri MS, Ravona-Springer R, Silverman JM, Haroutunian V. The effects of cardiovascular risk factors on cognitive compromise. Dialogues Clin Neurosci. 2009;11:201-212.

127. Schmidt R, Launer LJ, Nilsson LG, et al. CASCADE Consortium Magnetic resonance imaging of the brain in diabetes: the Cardiovascular Determinants of Dementia (CASCADE) Study. Diabetes 2004;53(3):687-692.

128. Skoog I, Gustafson D. Hypertension, hypertension-clustering factors and Alzheimer's disease. Neurol Res. 2003;25(6):675-680.

129. Farris W, Mansourian S, Chang Y, et al. Insulin-degrading enzyme regulates the levels of insulin, amyloid beta-protein, and the betaamyloid precursor protein intracellular domain in vivo. Proc Natl Acad Sci U S A. 2003;100(7):4162-4167.

130. Qiu WQ, Folstein MF. Insulin, insulin-degrading enzyme and amyloid- $\beta$ peptide in Alzheimer's disease: review and hypothesis. Neurobiol Aging. 2006;27(2):190-198.

131. Takeda S, Sato N, Rakugi H, Morishita R. Molecular mechanisms linking diabetes mellitus and Alzheimer disease: beta-amyloid peptide, insulin signaling, and neuronal function. Mol Biosyst. 2011; 7(6):1822-1827.
132. Vance JE. Dysregulation of cholesterol balance in the brain: contribution to neurodegenerative diseases. Dis Model Mech. 2012;5(6):746-755.

133. Robles Bayòn A, Gude Sampedro F. Inappropriate treatments for patients with cognitive decline. Neurologia. 2012;S0213-4853(12)00185-5.

134. Anstey KJ, von Sanden C, Salim A, O’Kearney R. Smoking as a risk factor for dementia and cognitive decline: a meta-analysis of prospective studies. Am J Epidemiol. 2007;166:367-378.

135. Kelly TN, Gu D, Chen J, et al. Cigarette smoking and risk of stroke in the Chinese adult population. Stroke. 2008;39:1688-1693.

136. Arntzen KA, Schirmer H, Wilsgaard T, Mathiesen EB. Impact of cardiovascular risk factors on cognitive function: the Tromsø study. Eur J Neurol. 2011;18:737-743.

137. de Toledo Ferraz Alves TC, Ferreira LK, Busatto GF. Vascular diseases and old age mental disorders: an update of neuroimaging findings. Curr Opin Psychiatry. 2010;23(6):491-497.

138. Barnes DE, Yaffe K. The projected effect of risk factor reduction on Alzheimer's disease prevalence. Lancet Neurol. 2011;10(9):819-828.

139. Fitzpatrick AL, Kuller LH, Lopez OL, et al. Midlife and late-life obesity and the risk of dementia: cardiovascular health study. Arch Neurol. 2009;66:336-342.

140. Kivipelto M, Ngandu T, Fratiglioni L, et al. Obesity and vascular risk factors at midlife and the risk of dementia and Alzheimer disease. Arch Neurol. 2005;62(10):1556-1560.

141. Whitmer RA, Gunderson EP, Barrett-Connor E, Quesenberry CP Jr, Yaffe K. Obesity in middle age and future risk of dementia: a 27 year longitudinal population based study. BMJ. 2005;330(7504):1360.

142. Martins IJ, Hone E, Foster JK, et al. Apolipoprotein E, cholesterol metabolism, diabetes, and the convergence of risk factors for Alzheimer's disease and cardiovascular disease. Mol Psychiatry. 2006; 11(8):721-736.

143. Pasinetti GM, Eberstein JA. Metabolic syndrome and the role of dietary lifestyles in Alzheimer's disease. J Neurochem. 2008;106:1503-1514.

144. Vercambre M-N, Grodstein F, Berr C, Kang JH. Mediterranean diet and cognitive decline in women with cardiovascular disease or risk factors. J Acad Nutr Diet. 2012;112(6):816-823.

145. Freund-Levi Y, Eriksdotter-Jonhagen M, Cederholm T, et al. Omega-3 fatty acid treatment in 174 patients with mild to moderate Alzheimer disease: OmegAD study: a randomized double-blind trial. Arch Neurol. 2006;63(10):1402-1408.

146. Geleijnse JM, Giltay EJ, Kromhout D. Effects of N-3 fatty acids on cognitive decline: a randomized, double-blind, placebo-controlled trial in stable myocardial infarction patients. Alzheimers Dement. 2012; 8(4):278-287.

147. Levitan EB, Wolk A, Mittleman MA. Consistency with the DASH diet and incidence of heart failure. Arch Intern Med. 2009;169(9):851-857.

148. Scarmeas N, Stern Y, Tang MX, Mayeux R, Luchsinger JA. Mediterranean diet and mild cognitive impairment. Arch Neurol. 2009;66:216-225.

149. Scarmeas N, Stern Y, Tang MX, Mayeux R, Luchsinger JA. Mediterranean diet and risk for Alzheimer's disease. Ann Neurol. 2006;59(6):912-921.

150. Scarmeas N, Stern Y, Mayeux R, Luchsinger JA. Mediterranean diet, Alzheimer disease, and vascular mediation. Arch Neuro. 2006; 63(12):1709-1717.

151. Román GC, Nash DT, Fillit H. Translating current knowledge into dementia prevention. Alzheimer Dis Assoc Disord. 2012;26(4): 295-299.

152. Larson EB, Wang L, Bowen JD, et al. Exercise is associated with reduced risk for incident dementia among persons 65 years of age and older. Annal Intern Med. 2006;144(2):73-81.

153. Aarsland D, Sardahaee FS, Anderssen S, Ballard C. Is physical activity a potential preventive factor for vascular dementia? A systematic review. Aging Ment Health. 2010;14:386-395.

154. Vreugdenhil A, Cannell J, Davies A, Razay G. A community-based exercise programme to improve functional ability in people with Alzheimer's disease: a randomized controlled trial. Scand J Caring Sci. 2012;26(1):12-19. 
155. Khachaturian AS, Zandi PP, Lyketsos CG, et al. Antihypertensive medication use and incident Alzheimer disease: the Cache County Study. Arch Neurol. 2006;63(5):686-692.

156. Feigin V, Ratnasabapathy Y, Anderson C. Does blood pressure lowering treatment prevents dementia or cognitive decline in patients with cardiovascular and cerebrovascular disease? J Neurol Sci. 2005;229-230:151-155.

157. Forette F, Seux ML, Staessen JA, et al. The prevention of dementia with antihypertensive treatment: new evidence from the Systolic Hypertension in Europe (Syst-Eur) study. Arch Intern Med. 2002; 162:2046-2052.

158. Tzourio C, Anderson C, Chapman N, et al. Effects of blood pressure lowering with perindopril and indapamide therapy on dementia and cognitive decline in patients with cerebrovascular disease. Arch Intern Med. 2003;163:1069-1075.

159. Guo Z, Fratiglioni L, Viitanen M, et al. Apolipoprotein E genotypes and the incidence of Alzheimer's disease among persons aged 75 years and older: variation by use of antihypertensive medication? Am J Epidemiol. 2001;153:225-231.

160. Launer LJ, Ross GW, Petrovitch H, et al. Midlife vascular risk factors and Alzheimer's disease in later life: longitudinal, population based study. Brit Med J. 2001;322:1447-1451.

161. Igase M, Kohara K, Miki T. The Association between Hypertension and Dementia in the Elderly. Int J Hypertens. 2012;2012:320648.

162. Peters R, Beckett N, Forette F, et al. Incident dementia and blood pressure lowering in the Hypertension in the Very Elderly Trial cognitive function assessment (HYVET-COG): a double-blind, placebo controlled trial. Lancet Neurol. 2008;7(8):683-689.

163. McGuinness B, Todd S, Passmore P, Bullock R. The effects of blood pressure lowering on development of cognitive impairment and dementia in patients without apparent prior cerebrovascular disease. Cochrane Database Syst Rev. 2006;2:CD004034.
164. Lee M, Saver JL, Chang B, Chang KH, Hao Q, Ovbiagele B. Presence of baseline prehypertension and risk of incident stroke: a meta-analysis. Neurology. 2011;77(14):1330-1337.

165. Benavente OR, White CL, Pearce L, et al. The Secondary Prevention of Small Subcortical Strokes (SPS3) study. Int J Stroke. 2011; 6(2):164-175.

166. Qiu C, Kivipelto M, von Strauss E. Epidemiology of Alzheimer's disease: occurrence, determinants, and strategies toward intervention. Dialogues Clin Neurosci. 2009;11(2):111-128.

167. Wolozin B, Bednar MM. Interventions for heart disease and their effects on Alzheimer's disease. Neurol Res. 2006;28:630-636.

168. Stanek KM, Gunstad J, Paul RH, et al. Longitudinal cognitive performance in older adults with cardiovascular disease: evidence for improvement in heart failure. J Cardiovasc Nurs. 2009;24(3):192-197.

169. Puccio D, Novo G, Baiamonte V, et al. Atrial fibrillation and mild cognitive impairment: what correlation? Minerva Cardioangiol. 2009;57:143-150.

170. Barber M, Tait RC, Scott J, Rumley A, Lowe GD, Stott DJ. Dementia in subjects with atrial fibrillation: hemostatic function and the role of anticoagulation. J Thromb Haemost. 2004;2(11):1873-1878.

171. Arikawa M, Kakinuma Y, Handa T, Yamasaki F, Sato T. Donepezil, antiAlzheimer's disease drug, prevents cardiac rupture during acute phase of myocardial infarction in mice. PLoS One. 2011;6(7):e20629.

172. Handa T, Katare RG, Kakinuma Y, et al. Anti-Alzheimer's drug, Donepezil, markedly improves long-term survival after chronic heart failure in mice. J Card Fail. 2009;15(9): 805-811.

173. Sink KM, Leng X, Williamson J, et al. Angiotensin-converting enzyme inhibitors and cognitive decline in older adults with hypertension: results from the Cardiovascular Health Study. Arch Intern Med. 2009 169(13):1195-1202.
Clinical Epidemiology

\section{Publish your work in this journal}

Clinical Epidemiology is an international, peer-reviewed, open access journal focusing on disease and drug epidemiology, identification of risk factors and screening procedures to develop optimal preventative initiatives and programs. Specific topics include: diagnosis, prognosis, treatment, screening, prevention, risk factor modification, systematic

\section{Dovepress}

reviews, risk \& safety of medical interventions, epidemiology \& biostatical methods, evaluation of guidelines, translational medicine, health policies \& economic evaluations. The manuscript management system is completely online and includes a very quick and fair peer-review system, which is all easy to use. 